\title{
NỘI SOI TOÀN BỘ CẮT U NHẦY NHĨ PHẢI
}

Nguyễn Hoàng Nam*, Nguyễn Công Hưu*, Nguyễn Trần Thuy ${ }^{*}$, Nguyễn Hũu Uớc ${ }^{* *}$, Lê Ngọ Thành ${ }^{*}$

\section{TÓM TẮT}

Đặt vấn đề: Phẫu thuật tim nội soi ít xâm lấn đang dần trở thành xu hướng thay thế dần phẫu thuật mở xương ức với những kết quả tích cực, trong đó điều trị bệnh lý u nhầy nhĩ. Báo cáo của chúng tôi nhằm đưa ra kết quả ban đầu trong điều trị nội soi toàn bộ cắt bỏ khối u nhầy nhĩ phải.

Đối tượng và phuơng pháp nghiên cứu: Mô tả, hồi cứu hồ sơ bệnh án. 5 bệnh nhân được chẩn đoán u nhầy nhĩ phải được phẫu thuật nội soi toàn bộ cắt khối u nhầy với tim đập trong thời gian từ tháng 3/2019 đến tháng 10/2020. Đánh giá qua các thông số thời gian mổ, thở máy, nằm hồi sức và hậu phẫu sau mổ.

Kết quả: Tổng số 5 bệnh nhân ( 4 nữ; 1 nam). Tuổi trung bình $57 \pm 6,92$. Thời gian mổ $3,1 \pm 0,5$ giờ, chạy máy tim phổi nhân tạo $101,2 \pm$ 32,8 phút, thời gian nằm hồi sức $40,4 \pm 17,3$ giờ, thời gian hậu phẫu $4,4 \pm 1,7$ ngày. Không có tử vong bệnh viện, không chảy máu sau mổ, không tai biến tắc mạch khí.

Kết luận: Phẫu thuật nội soi toàn bộ cắt bỏ u nhầy nhĩ phải khả thi, có thể thực hiện được, nên được nghiên cứu và áp dụng.

Tù khoá: u nhầy, it xâm lấn, nội soi

\section{TOTAL ENDOSCOPIC RESECTION OF RIGHT ATRIAL MYXOMA}

\section{ABSTRACT}

Objective: Minimally invasive endoscopic heart surgery is gradually becoming a trend to replace sternotomy with good results, including the treatment of atrial myxoma. Our report is intended to provide preliminary results for the total endoscopic resection of right atrial myxoma.

Methods and materials: Describe and retrospect medical records. 5 patients diagnosed with right atrial myxoma undergo total endoscopic surgery to resection the tumor with a beating heart between March 2019 and October 2020. Evaluation by parameters of surgery time, mechanical ventilation, resuscitation, postoperative postoperative.

Results: A total of 5 patients (4 females; 1 male). Average age $57 \pm 6.92$. Surgery time $3.1 \pm$ 0.5 hours, circultion extracorporelle times $101.2 \pm$ 32.8 minutes, recovery time $40.4 \pm 17.3$ hours, postoperative time $4.4 \pm 1,7$ days. There was no hospital death, no postoperative bleeding, and no stroke.

Conclusion: Total endoscopic surgery to resection right atrial myxoma be feasible, feasible, and should be studied and applied.

Key words: myxoma, minimally invasive, endoscopy

\section{TỔNG QUAN}

U nguyên phát ở tim thì khá hiếm, tỉ lệ mắc khoảng $0,17-19 \%$. Ba phần tư trong số đó là lành

\footnotetext{
* Khoa Phẫu thuật Tim mạch Lồng ngực - Trung tâm Tim mạch Bệnh viện $E$

** Trung tâm tim mạch và lồng ngục - Bệnh viện hũu nghị Việt Đức Người chịu trách nhiệm khoa học: Lê Ngọc Thành

Ngày nhận bài: 13/01/2021 - Ngày cho phép đăng: 08/04/2021
} 
tính. Gần nửa trong số lành tính là u nhầy. U nhầy ở tim thì chủ yếu phát triển ở tầng nhĩ với khoảng $75 \%$ hình thành trong nhĩ trái, hơn 15\% hình thành trong nhĩ phải, số còn lại có thể gặp ở thất hoặc hai tầng nhĩ. Tuỳ vị trí, tính chất và kích thước của khối u nhầy nhĩ có thể gây các biến chứng tắc mạch, thần kinh, cản trở dòng máu trong tim, nhồi máu phổi hoặc phù phổi. Điều trị phẫu thuật cắt bỏ $\mathrm{u}$ cần được làm sớm khi được chẩn đoán [1]. Phẫu thuật ít xâm lấn hoặc robotic nội soi toàn bộ đã trở thành xu thế và được ứng dụng ngày càng nhiều trong phẫu thuật tim mạch. U’u điểm của phương pháp này là tính thẩm mỹ, ít chấn thương và bệnh nhân hồi phục sớm[2]. Dựa trên những kết quả khả quan của phẫu thuật ít xâm lấn trong điều trị một số bệnh van hai lá, thông liên nhĩ và thông sàn nhĩ thất bán phần[3,4], chúng tôi đã tiến hành mổ ít xâm lấn nội soi toàn bộ trong điều trị bệnh lý u nhầy nhĩ phải chỉ với ba vết rạch (chiều dài $5 \mathrm{~mm}, 10 \mathrm{~mm}$, $12 \mathrm{~mm}$ ) cho việc sử dụng các dụng cụ phẫu thuật. Báo cáo này nhằm đưa ra kinh nghiệm ban đầu cho kĩ thuật này.

\section{ĐỐI TƯợNG VÀ PHƯƠNG PHÁP} NGHIÊN CỨU

Năm bệnh nhân (04 nữ, 01 nam) với độ tuổi trung bình $57 \pm 6,92$ đã trải qua phẫu thuật nội soi toàn bộ $3 \mathrm{D}$ cắt bỏ khối u nhầy nhĩ phải trong khoảng thời gian từ 03/2019 đến 10/2020. Tất cả các bệnh nhân đều được chẩn đoán là u nhầy nhĩ phải dựa trên hình ảnh siêu âm thành ngực, và được chụp cắt lớp vi tính ngực bụng, sọ não để đánh giá tổng thể. Trên cắt lớp vi tính có thể thấy được vị trí tính chất khối u ngoài ra còn giúp tầm soát toàn thân trong trường hợp các khối u từ các cơ quan khác, hoặc những biến chứng gây thuyên tắc mạch phổi. Các bệnh nhân đều không có bệnh lý về mạch máu, không có tiền sử mổ lồng ngực trước đây. Các bệnh nhân được siêu âm kiểm tra trước khi ra viện. Báo cáo dựa trên kết quả hồi cứu hồ sơ bệnh án đánh giá các thông số về thời gian mổ, thời gian chạy máy tim phổi nhân tạo, số lượng máu truyền, thời gian thở máy, thời gian nằm hồi sức và thời gian hậu phẫu.

Dưới gây mê nội khí quản hai nòng, bệnh nhân nằm tư thế nghiêng phải 30 độ, tay duỗi dọc theo thân, đầu dò siêu âm thực quản được đặt sẵn. Thiết lập tuần hoàn ngoài cơ thể ngoại vi bằng cách đặt ống động mạch-tĩnh mạch vào bó động tĩnh mạch đùi phải, đặt ống tĩnh mạch chủ trên vào tĩnh mạch cảnh trong phải. Tất cả quy trình thiết lập tuần hoàn ngoại vi được thực hiện với dụng cụ dây dẫn đường và kiểm soát dưới siêu âm thực quản. Các cổng vào (trocart) kích thước $5 \mathrm{~mm}, 10 \mathrm{~mm}, 12 \mathrm{~mm}$ được đặt lần lượt vào các khoang liên sườn 3 nách trước, 5 nách giữa và 5 đường giữa xương đòn bên lồng ngực phải. Chạy máy tim phổi, thông khí một bên phổi trái. Dưới nội soi mở màng tim, luồn dây thắt tĩnh mạch chủ trên. Bơm carbon dioxid vào phẫu trường, mở nhĩ phải theo đường song song với rãnh nhĩ thất. Cắt bỏ u nhầy, cho vào túi chuyên dụng nội soi. Đóng nhĩ phải, lấy bỏ khối u nhầy qua cổng vào phẫu thuật $12 \mathrm{~mm}$. Tất cả làm dưới tim đập, không sử dụng dung dịch liệt tim. Kiểm tra lại bằng siêu âm thực quản và kiểm soát khí trong buồng tim. Đặt dẫn lưu màng tim và màng phổi qua các cổng phẫu thuật. 


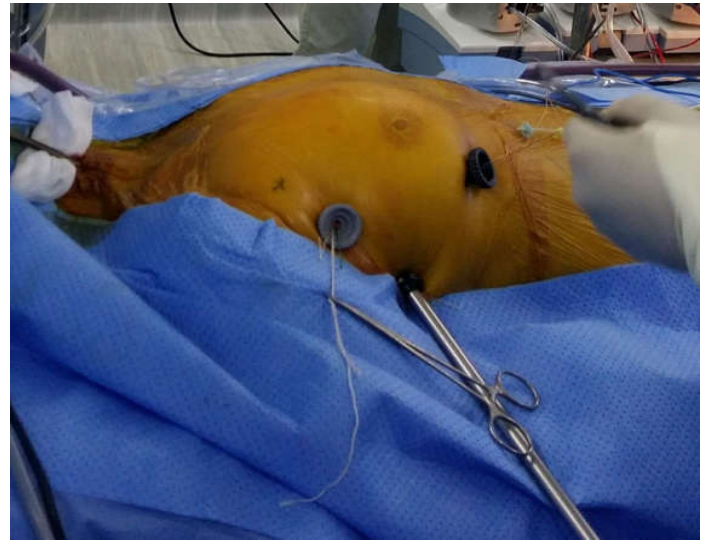

Hinh 1. Vị trí các lỗ trocart

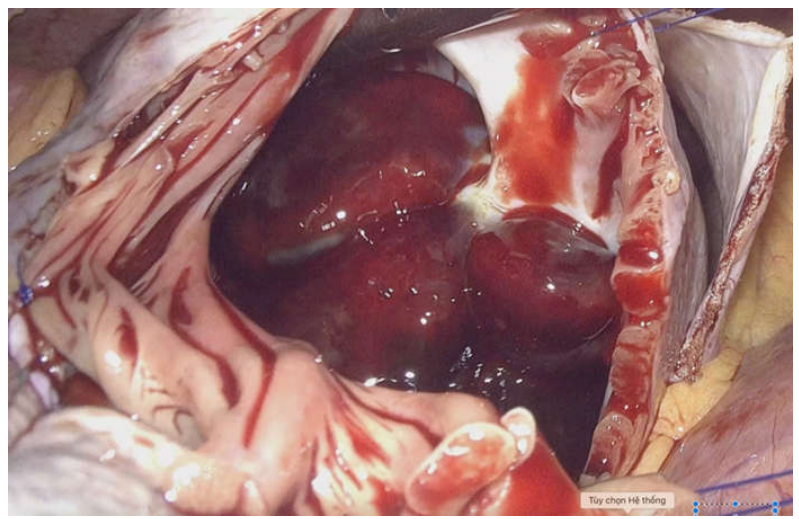

Hình 2. Khối u nhầy trong nhĩ phải

\section{KẾT QUẢ}

Không có tử vong bệnh viện, không bệnh nhân nào phải chuyển mở xương ức. Khối u nhầy được lấy bỏ hoàn toàn. Thời gian mổ $3,1 \pm 0,5$ giờ, chạy máy tim phổi nhân tạo 101,2 $\pm 32,8$ phút, thời gian nằm hồi sức 40,4 \pm 17,3 giờ, thời gian hậu phẫu 4,4 $\pm 1,7$ ngày. Không có biến chứng nào liên quan đến tắc mạch khí, mạch máu ngoại biên, mổ lại vì chảy máu.

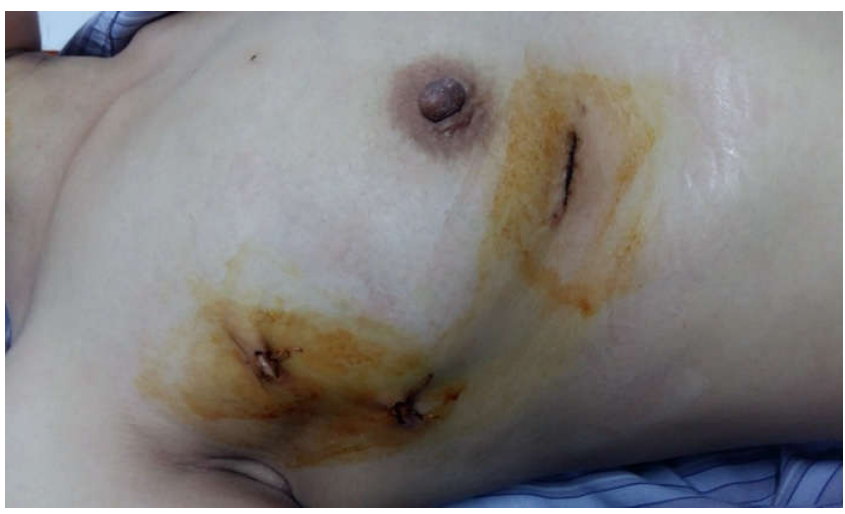

Hinh 3. Sẹo mổ sau phẫu thuật

\section{BÀN LUẬN}

Phẫu thuật cắt bỏ khối u nhầy nhĩ thường được tiến hành với đường mở xương ức truyền thống. Tuy nhiên hiện nay với sự tiến bộ của khoa học công nghệ, sự cải tiến về các dụng cụ phẫu thuật cũng như chạy máy tim phổi nhân tạo đã cho phép thực hiện qua những đường rạch nhỏ hơn ít xâm lấn hoặc nội soi toàn bộ sử dụng robotic. Nhiều nghiên cứu đã chỉ ra được những ưu điểm của phẫu thuật ít xâm lấn trong điều trị các bệnh lý van hai lá [5], thông liên nhĩ [6].

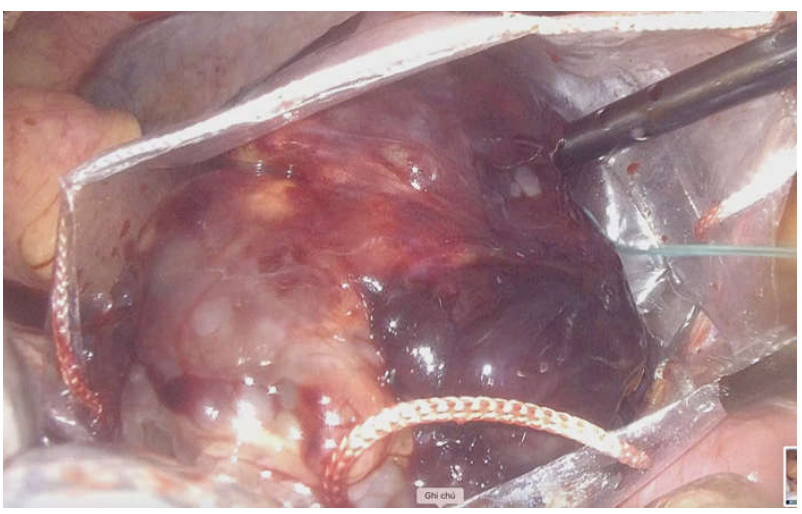

Hinh 4. Sử dụng túi nội soi lấy khối u nhầy

Hầu hết các báo cáo đều nêu được ưu điểm của phẫu thuật ít xâm lấn như tính thẩm mỹ, ít đau, số lượng máu truyền ít, bênh nhân sớm hồi phục. Với bệnh lý u nhầy nhĩ cũng có nhiều báo cáo đưa ra kết quả của phẫu thuật ít xâm lấn trong điều trị bệnh lý này. Trong nghiên cứu của Andres M. Pineda đã tổng hợp lại 7 báo cáo khác nhau của phẫu thuật ít xâm lấn qua mở ngực phải trong phẫu thuật cắt bỏ u nhầy nhĩ so với mở toàn bộ xương ức. Các tác giả đã nhận thấy rằng, với đường mở ngực phải, thời gian 
bệnh nhân nằm hồi sức và nằm viện ngắn hơn, và tỉ lệ tử vong tương đương với đường mở toàn bộ xương ức[7]. Một báo cáo khác của Changqing Gao và cộng sự thông báo sự thành công của việc áp dụng phẫu thuật nội soi toàn bộ sử dụng robot De Vinci cho 19 bệnh nhân u nhầy với kết quả rất tốt. Điểm nổi bật là tính thẩm mỹ với sẹo mổ chính là các cổng vào của các dụng cụ phẫu thuật, bệnh nhân không phải cưa xương ức, cơ thành ngực không bị thuơng tổn nhiều, ít đau sau mổ[8]. Với đặc điểm của tình hình thực tế và thành công trong triển khai phẫu thuật nội soi toàn bộ không có robot hỗ trợ trong điều trị bệnh lý thông liên nhĩ[9], cùng với những kinh nghiệm sẵn có, chúng tôi tiến hành phẫu thuật nội soi toàn bộ không có robot hỗ trợ và tim đập để cắt bỏ khối u nhầy nhĩ phải. Khối u nhầy nhĩ phải đã được cắt bỏ hoàn toàn ở 5 bệnh nhân chỉ với ba vết rạch da nhỏ cho lỗ vào của ống nội soi và dụng cụ phẫu thuật, ít hơn so với mổ robot của Changing Gao. Thời gian chạy máy trong nhóm bệnh nhân của chúng tôi là $101,2 \pm 32,8$ phút, tương đồng với báo cáo của Changing Gao là $98 \pm 20,5$ phút và báo cáo của Douglas A.Murphy là $103 \pm 40$ phút[10]. Một ưu điểm nữa của phương pháp này là không sử dụng liệt tim, chủ động để tim đập trong quá trình lấy bỏ khối u. Giảm được những nguy cơ của liệt tim đem đến khi đặt kim vào gốc động mạch chủ. Phương pháp này đã được nhiều tác giả báo cáo trước đây. Như trong các nghiên cứu của Umakanthan $\mathrm{R}$ hoặc Chang Chau-Hsiung các tác giả đều chủ động không liệt tim, giữ tim rung hoặc đập ở nhiệt độ bình thường[11][12]. Thời gian nằm hồi sức $1,6 \pm 0,7$ ngày, thời gian hậu phẫu 4,4 $\pm 1,7$ ngày. Cả hai thông số này cũng tương đồng với nghiên cứu của Changing Gao và Douglas A. Murphy [10]. Cho thấy bệnh nhân hồi phục nhanh chóng, ra viện khá sớm. Không có biến chứng nào về thần kinh, tắc mạch, chảy máu mổ lại. Tuy nhiên đây chỉ là báo cáo thành công trên một số ca lâm sàng nên chỉ có một số điểm chúng tôi nhận thấy cần lưu ý là: khi phát hiện bệnh nhân u nhầy nhĩ phải nên để bệnh nhân hạn chế đi lại do khối u nhầy thường mủn, nhiều múi dễ bị rơi rụng gây ra các biến chứng như tắc mạch phổi, trôi vào buồng thất phải, cản trở hoạt động van ba lá. Khi thiết lập tuần hoàn ngoài cơ thể ngoại vi đặt ống tĩnh mạch chủ trên và dưới sử dụng dây dẫn đường, nguy cơ khi luồn dây dẫn và ống tĩnh mạch có thể làm vỡ và phát tán khối u. Để tránh nguy cơ này chúng tôi chủ động đặt siêu âm thực quản để quan sát được dây dẫn và ống tĩnh mạch hạn chế tác động vào khối u. Đối với nguy cơ tắc mạch khí khi mở nhĩ phải cần phải phối hợp nhiều kĩ thuật : đầu thấp, bơm carbon dioxid. Chỉ mở nhĩ phải khi đã bơm đầy carbondioxid trong lồng ngực, và bơm liên tục trong quá trình cắt bỏ khối u và đóng nhĩ phải. Khi lấy bỏ khối u cần sử dụng túi lấy bệnh phẩm cho khối u vào túi ngay sau khi cắt khối $\mathrm{u}$, tránh nguy cơ phát tán khối u.

\section{KẾT LUẬN}

Với thành công ban đầu với mổ nội soi toàn bộ cắt $\mathrm{u}$ nhầy nhĩ phải trên 5 bệnh nhân đưa ra những gợi ý rằng việc áp dụng mổ nội soi toàn bộ cho điều trị cắt u nhầy nhĩ là khả thi và xứng đáng được nghiên cứu áp dụng một cách rộng rãi hơn.

\section{TÀI LIẸU THAM KHẢO}

1. Reynen K . Cardiac myxomas. N Engl J Med. 1995; 333(24):1610-1617.

2. Modi P, Hassan A, Chitwood WR Jr. 
Minimally invasive mitral valve surgery: a systematic review and meta-analysis (2008). Eur J Cardiothorac Surg. 2008; 34:943-952

3. Nguyễn Công Hựu, Nguyễn Hoàng Nam, Nguyễn Trung Hiếu và cộng sự. Phẫu thuật với nội soi lồng ngực hỗ trợ đóng thông liên nhĩ dưới tuần hoàn ngoài cơ thể, tim đập, không cặp động mạch chủ, Phẫu thuật noi soi và nội soi ViệtNam,2014; 3(3): 29-33

4. Casselman FP, Slyke SV, Dom H, Lambrechts DL, Vermeulen Y, Vanermen H. Endoscopic mitral valve repair: feasible, reproductive, and durable. J Thorac Cardiovasc Surg. 2003; 125:273-282

5. Schmitto JD, Mokashi SA, Cohn LH. Minimally-Invasive Valve Surgery. Journal of the American College of Cardiology. 2010; 56(6):455-462

6. Argenziano M, Oz MC, Kohmoto $\mathrm{T}$ et al. Totally endoscopic atrial septal defect repair with robotic assistance. Circulation. 2003;108 Suppl 1: II191-II194

7. Pineda AM, Santana O, Cortes-
Bergoderi M, Lamelas J. Is a minimally invasive approach for resection of benign cardiac masses superior to standard full sternotomy? Interact Cardiovasc Thorac Surg. 2013;16(6):875-879.

8. Gao C, Yang M, Wang $\mathrm{G}$ et al. Excision of atrial myxoma using robotic technology. $\mathrm{J}$ Thorac Cardiovasc Surg. 2010 May;139(5):1282-1285

9. Đặng Quang Huy, Phạm Thị Kim Lan, Nguyễn Công Hựu. Phẫu thuật nội soi toàn bộ không có Robot hỗ trợ, tim đập vá thông liên nhĩ: kinh nghiệm ở một trung tâm. Tạp chí phẫu thuật tim mạch và lồng ngực Việt Nam. 2017; 18:29-35.

10. Murphy DA, Miller JS, Langford DA. Robot-assisted endoscopic excision of left atrial myxomas. J Thorac Cardiovasc Surg. 2005 Aug;130(2):596-597.

11. Chang CH, Lin PJ, Chu JJ et al. Videoassisted cardiac surgery in closure of atrial septal defect. Ann Thorac Surg. 1996; 62(3):697 - 701.

12. Umakanthan $R$, Leacche $M$, Petracek MR et al (2008). Safety of Minimally Invasive Mitral Valve Surgery Without Aortic Cross-Clamp. Ann Thorac Surg. 2008; 85(5): 1544 - 1550. 